\title{
Models of Periodontal Pathogenesis
}

\author{
Pushpa Latha $\mathrm{T}^{1}$, Satyanarayana $\mathrm{D}^{2}$, Rajababu $\mathrm{P}^{3}$, Vikram Reddy $\mathrm{G}^{4}$
}

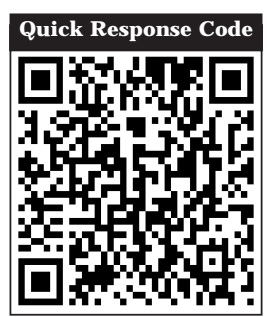

doi: $10.5866 / 2016.8 .10033$

1Post Graduate student

2Professor, M.D.S

${ }^{3}$ HOD \& Professor, M.D.S

${ }^{4}$ Reader M.D.S

Department of Periodontics,

Kamineni Institute of Dental Sciences,

Narketpally, Nalgonda, Telangana

\section{Article Info:}

Received: J anuary 7, 2016

Review Completed: February 8, 2016

Accepted: March 9, 2016

Available Online: May, 2016 (www.nacd.in)

(C) NAD, 2016 - All rights reserved

Email for correspondence:

drpushpalathamds@gmail.com

\begin{abstract}
:
Chronic adult periodontitis is a multifactorial disease. Early histopathological observations described linear model of pathogenesis in periodontal disease. After that the bacterial activation of immuno inflammatory mechanisms, environmental and genetic factors modified the dinical phenotype of periodontal disease which led to the formulation of non-linear conceptual models. However, these models did not capture the dynamic nature of the biochemical processes. With emerging genomic, proteomic, and metabolomic data and systems biology tools for interpreting data, a multilevel hierarchial model and biological systems model has been proposed to describe the basic elements of a new model of pathogenesis. It is hoped that improved conceptual models of pathogenesis will assist in focusing new research and speed the translation of new data into practical applications.
\end{abstract}

Key words: Pathogenesis, Periodontal disease, Periodontitis, Systems biology.

\section{Introduction:}

Periodontitis is a complex disease in which disease expression involves intricate interactions of the biofilm with the host immuno inflammatory response and subsequent alterations in bone and connective tissue homeostasis. A model of the pathogenesis of periodontitis based on systems biology approaches should allow investigators to better communicate the interrelatedness of various biologic components involved in the initiation and resolution of disease.

\section{Concepts of the pathogenesis of periodontal disease:}

Linear model (Figure 1): In mid-1960's Human and animal experimental evidence demonstrated the critical role of bacteria in the initiation of gingivitis and periodontitis which led to a clear concept of pathogenesis, prevention and treatment of periodontal diseases. Linear model proposed by Loe et.al. implicated bacterial plaque deposits as the primary, direct factor in the development of periodontitis and resulted in the abandonment of former concepts that involved nonbacterial factors, such as trauma from occlusion, systemic conditions, and diet. ${ }^{1}$

Drawbacks: This model could not capture the dynamic nature of the biochemical processes, i.e., those innate differences among individuals and changes in environmental factors which may accelerate biochemical changes or dampen that shift.

Basic conceptual model - circa model (Figure 2): During 1970's and early 1980's Research and scientific discussions based on the simple concept of bacterial causation led to great advances in knowledge. Specific Gram-negative, anaerobic, or microaerophilic bacteria were implicated in the causation of periodontitis, and the protective and 
destructive roles of the immuno inflammatory responses and the critical role of polymorphonuclear neutrophils (PMNs) in contributing to periodontal damage were described. ${ }^{2-8}$ Finally, during this period, the initiation and progression of periodontitis was described in terms of distinctive histopathological characteristics that provided insights into the pathogenesis processes. ${ }^{9}$ The most important aspect of this model is that a distinction between the role of the microbial challenge and immuno inflammatory mechanisms in the pathogenesis of periodontal disease was apparent.

Drawbacks: This model could not explain some clinical disease patterns, or phenotypes which had characteristic bacteria and host responses.

The extensive research through the mid-1980s led to critical refinements in the pathogenesis concept.I n most of the models of the late 1980s; specific bacteria initiated the disease process by activating host responses, which were protectiveand destructive. The actual destruction of connective tissue and bone resulted primarily from activated tissue mechanisms, such as matrix metalloproteinases, interleukin-1, and prostaglandins. ${ }^{10}$

Critical pathway model (Figure 3): In 1990 advances has led to the understanding the cellular and molecular interaction which resulted in periodontal disease progression, where understanding regarding these elements had led to critical pathway of pathogenesis by Offenbacher in 1996. ${ }^{11}$

To add further complexity to the earlier conceptual models, there was a growing appreciation during this period which highlighted the genetic variations in the development and severity of periodontal disease which accounted for 30\% to $60 \%$ of variability. Genetic differences among individuals seemed to be a significant determinant of risk for periodontal disease and, most importantly, there were gene variations that altered host responses and modified the clinical severity of disease. ${ }^{12}$ With new knowledge of the various factors contributing to periodontal disease, the clinical phenotype is not simply the microbial challenge translated by a standard host response but also smoking and diabetes were shown to be powerful determinants of disease severity. ${ }^{13,14}$ This has led to raise several questions like

- Does periodontitis affects all individuals uniformly?

- Do progression is continuous \& linear throughout life?
- Do disease severity is directly correlated to plaque levels?

Non-linear model (Figure 4): The basic conceptual model of periodontitis was revised in 1997, in great part to acknowledge that various risk factors operated by modifying host responses led to changes in disease expression. ${ }^{15}$ In this model, host immuno-inflammatory mechanisms areactivated by bacterial products. Such activation of the host response induces the expression of antibodies as well as activating PMNs in an attempt to control the microbial challenge in the gingival sulcus. In addition, cytokines and prostanoids, as well as matrix metalloproteinases activated through the host response, may stimulate damage to connective tissue and bone and shape the clinical presentation of disease. ${ }^{16}$ The model implied that there were a range of host responses and a range of clinical expressions of disease that were primarily determined by genetic and environmental factors that modified the host response. Each combination of genetic variations and environmental factors may define a specific gene expression pattern. ${ }^{17}$

Although many of the concepts presented in the 1997 non-linear model of periodontal disease remain relevant today, there have been advances in knowledge about periodontal disease that may alter our models of pathogenesis.

First, it was demonstrated that microbial periodontal pathogens are found in ecologic complexes, and an ecologic shift can lead to emergence of a specific set of microbial pathogens. Second, a number of studies confirmed that a small group of disease modifiers, including diabetes, genotype, and smoking, contribute strongly to individual patient differences in the susceptibility to periodontitis. Third, many studies described associations between periodontitis and other diseases, Such as cardiovascular disease, and potentially explained such associations through bacterial seeding, common inflammatory mechanisms, and/or common modifying factors. Fourth, there was an extension of knowledge about specific bacterial mechanisms and immuno inflammatory mechanisms in periodontitis.

During the same period of time, there were substantial advances in knowledge about chronic diseases in general that have influenced our thinking about the pathogenesis of periodontitis. First, inflammatory mechanisms were recognized as being common to many chronic diseases, such as cardiovascular disease. Second, periodontitis and other chronic diseases were acknowledged as "complex" in character.Complex biologic traits, have 

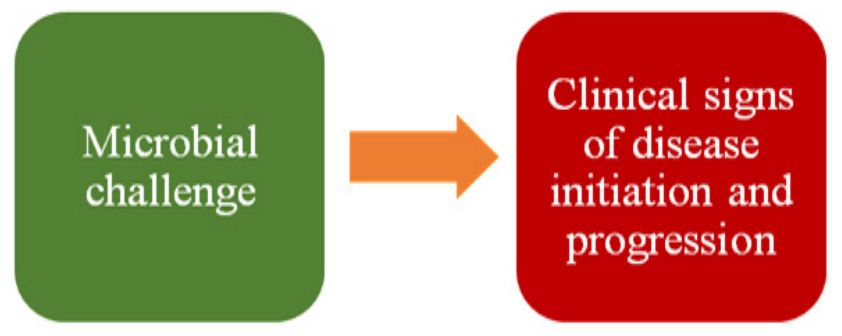

Figure 1: Early linear model depicting the principal etiologic role for bacteria in the initiation and progression of periodontal disease.

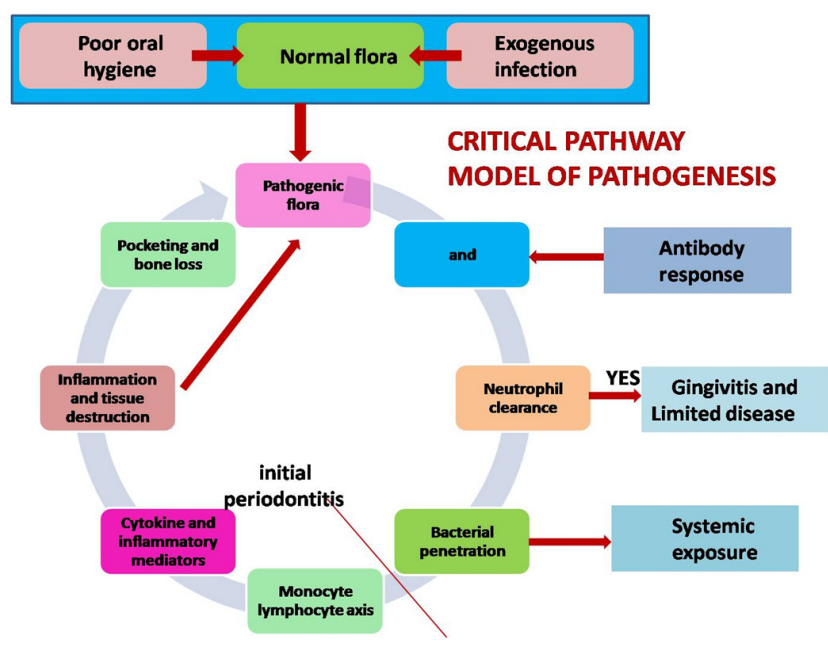

Figure 3: Critical pathway model (Offenbacher, 1996)

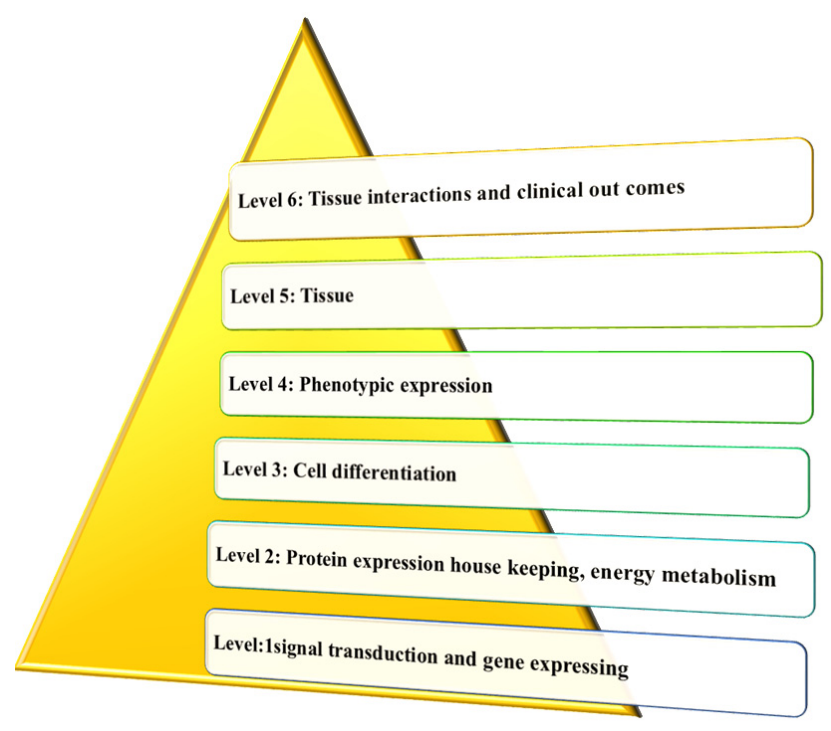

Figure 5: Multilevel hierarchal model

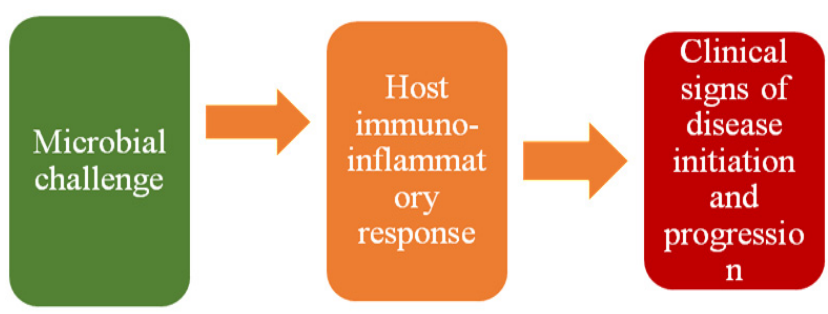

Figure 2: Circa 1980s model (I vanyi L , Lehner T , 1980 ) emphasizing a central role for the host immuno-inflammatory response in the clinical development and progression of periodontal disease.

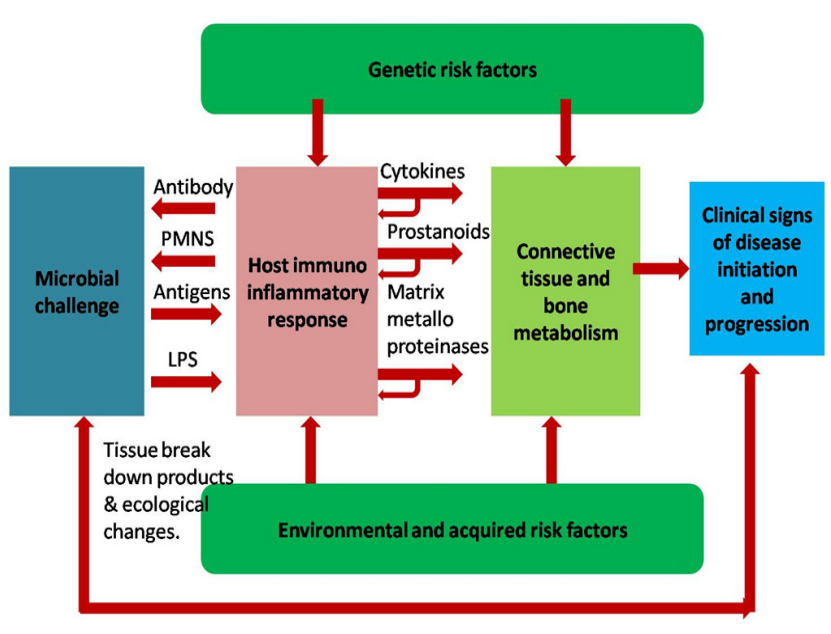

Figure 4: Non- linear model, 1997

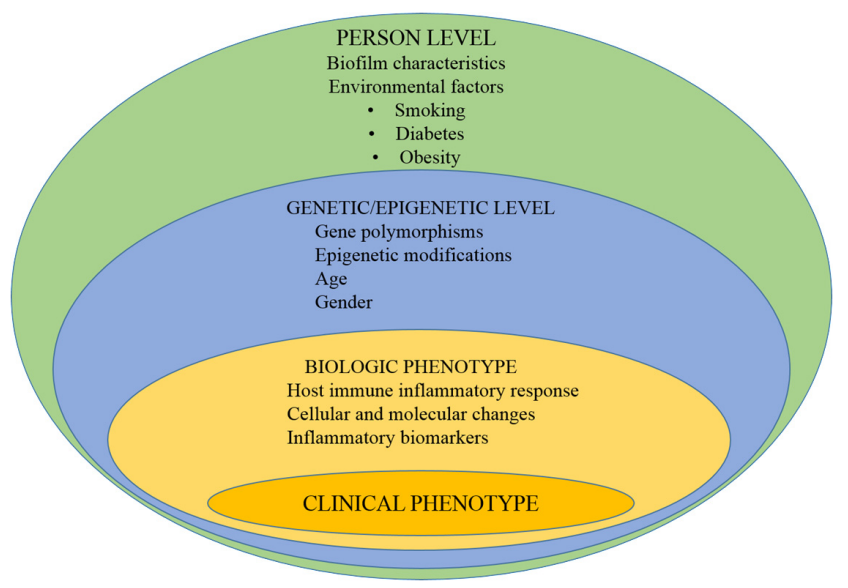

Figure 6: Biologic systems model 
molecular networks that display emergent properties as a result of contributions from genetic and environmental factors. Third, although the biology is complex, the integrated behavior of the entire system can be studied using new simulation tools. The fourth factor-complex diseases that may be applicable to models of periodontal pathogenesis involves the roles of environmental factors.

Multilevel hierarchal model (Figure 5): The 1997 conceptual model of the pathogenesis of periodontal diseasearestill relevant today; however, the framework would now be based on a multilevel hierarchical organization, and the interactions are reflected in gene, protein, and metabolite expression patterns. The top layer includes clinically observable parameters, such as smoking, whereas the levels below include tissue, cellular, and sub cellular layers, each divided into biologic networks. At the lower levels, the biologic expression of the immuno inflammatory network and bone and connective tissue network are determined by the microbial factors and the specific combination of environmental factors and gene variations for that individual.

New Biological systems model (Figure 6): Building a systems biology model of periodontitis presents substantial requirements and challenges, but investigators have started to provide data on the entities and gene and protein expressions associated with certain components of the periodontal model. This model involves bacterial components, environmental factors such as smoking and diabetes. ${ }^{18}$

This provides a frame work for viewing the contributions and relative importance of all components that contribute to the clinical presentation of the periodontal disease and individual response, including cytokines and lipid mediators, produced by the host, as well as alterations in bone and connective tissue, can be clearly characterized by a specific pattern of gene, protein, and metabolite expression. The expressed proteins and metabolites provide feedback on the system to regulate the host response and bone and connective tissue, while helping to control the bacterial challenge.

\section{Conclusion:}

Over the past 50 years, a number of conceptual models describing the pathogenesis of periodontal disease have been presented based on existing knowledge at the time. The more recently explored bi ol ogic systems approach to modeling holds promise for revolutionizing conceptual models of the past by providing a comprehensive view of the disease process as a complex regulatory network. Within this framework, discrete modules of genetic, environmental, and other modifying factors would define a specific expression pattern that represents the shift from health to disease.

\section{References:}

1. Page RC, Kornman KS. The pathogenesis of human periodontitis: An introduction. Periodontol 2000 1997; 14:911.

2. Slots J . Subgingival microflora and periodontal disease. J Clin Periodontol 1979; 6:351-82.

3. Socransky SS. Microbiology of periodontal disease Present status and future considerations. J Periodontol 1977; 48:497-504.

4. Listgarten MA. The role of dental plaque in gingivitis and periodontitis. J Clin Periodontol 1988; 15:485- 7.

5. Newman MG. Anaerobic oral and dental infection. Rev I nfect Dis 1984; 6:107-14.

6. Theilade E. The non-specific theory in microbial etiology of inflammatory periodontal diseases. J Clin Periodontol 1986; 13:905-11.

7. Van Dyke TE. Role of the neutrophil in oral disease: Receptor deficiency in leukocytes from patients with juvenile periodontitis. Rev Infect Dis 1985; 7:419-25.

8. Genco RJ, Van Dyke TE, Levine MJ, Nelson RD, Wilson ME. 1985 Kreshover lecture. Molecular factors influencing neutrophil defects in periodontal disease. J Dent Res 1986; 65:1379-91.

9. Page RC, Offenbacher S, Schroeder HE, Seymour GJ , Kornman KS. Advances in the pathogenesis of periodontitis: Summary of developments, clinical implications and future directions. Periodontol 2000 1997; 14:216-48.

10. Kenneth S. Kornman Mapping the Pathogenesis of Periodontitis: A New Look J Periodontol 2008; 79:1560-8.

11. Page RC, Kornman KS. The pathogenesis of human periodontitis: An introduction. Periodontol 2000 1997; 14:911.

12. Lindhe J, Hamp SE, Loe H. Plaque induced periodontal disease in beagle dogs. A 4-year clinical, roentgenographical and histometrical study. J Periodontal Res 1975; 10:243-55.

13. Loe H, Anerud A, Boysen H, Morrison E. Natural history of periodontal disease in man. Rapid, moderate and no loss of attachment in Sri Lankan laborers 14 to 46 years of age. J Clin Periodontol 1986; 13:431-45.

14. Kornman KS, Crane A, Wang HY, et al. The interleukin-1 genotype as a severity factor in adult periodontal disease. J Clin Periodontol 1997; 24:72-7.

15. Bergstrom J . Periodontitis and smoking: An evidence based appraisal. J Evid Based Dent Pract 2006; 6:33-41.

16. Genco RJ . Current view of risk factors for periodontal diseases. J Periodontol 1996; 67(10):1041-9.

17. Page RC, Kornman KS. The pathogenesis of human periodontitis: An introduction. Periodontol 2000 1997; 14:911.

18. Offenbacher S, Barros SP, Singer RE, Moss K, Williams RC Beck J D. Periodontal disease at the biofilm-gingival interface. J Periodontol 2007; 78:1911-25. 